\title{
CEREBRAL V'ASOSPASM
}

\author{
ANTONIO A. F. DE SALLES *
}

There are essentially two principal end points in cerebrosvascular regulation: maintenance of an adequate supply of blood and energy-yielding substrates to the brain, despite the imposition of physiological or pathological stresses such as hypoxemia or reduced perfusion pressure, and precise and rapid coupling of regional cerebral bload flow (CBF) to changes in neuronal requirements 32 . These two features of the cerebral circulation are met under a complex control of the cerebral vasculature by a still unknown mechanism of autoregulation This autoregulation depends on direct action of metabolites and/or pressure stimuli in the smooth muscle vessel wall $26,28,32$. In several pathological conditions the cerebrovascular autoregulation can be impaired, not in toto, but in variable degrees 32. Cerebral vessels no longer obey the physiological stimuli, but assume a steady state tonus not coupled with the brain metabolism of their area of supply 39. They can remain dilated or contracted. In the last case, the phenomenon is known as cerebral vasospasm. Vasospasm can be due either to an abnormal responsiveness of the vascular smooth muscle cells or to abnormally high levels of endogenous vasoconstrictor substances $\mathbf{5 1}$. It remains unclear as to whether vasospasm is a normal or abnormal contraction or failure relaxation of arterial smooth muscle cells or whether it represents a cytoarchitectural thickening in the vessel wall 23 . Cerebral vasospasm occurs in pathological circumstances such as migraine, subarachnoid hemorrhage ( $\mathrm{SAH}$ ), head trauma, post-cerebral ischemia and/or hypoxia 13,23,24,51. Cerebral vasospasm is particularly important in SAH. While the surgical morbidity and mortality of uncomplicated cerebral aneurysm approaches that of a cholecystectomy 24 , it has been demonstrated that the leading cause of death and disability in patients with aneurysmal $\mathrm{SAH}$ is cerebral vasospasm 23 . The cerebral vasospasm that follows $\mathrm{SAH}$ is a biphasis phenomenon. It consist of a relatively short early phase (minutes) ${ }^{2}$, reversible by antagonists of smooth muscle contraction and a late and long-lasting phase of spasm (weeks), refractory to every muscle relaxant 23,45 . Each phase has a different physiopathology 23 , with similarities to other causes of cerebral vasospasm. Thus, SAH is a good model for the study of cerebral vasospasm. Much as been learned about the cerebral vasospasm that follows SAH since it was first described 30 years ago 13 . This accumulated knowlege can ben applied to other diseases where cerebral vasospasm is present. It can also provide further understanding of the physiological control of cerebrovascular smooth muscle $23,32,51$. 
Vasospasm following $\mathrm{SAH}$ will be elaborated in this review. Hemodynamic repercussions, lesions in the vessel walls and biochemical aspects of cerebral vasospasm wil be discussed. The applicability of the concepts obtained in the $\mathrm{SAH}$ research to other causes of cerebral vasospasm will be mentioned en passage.

\section{HEMODYAMIC REPERCUSSIONS OF CEREBRAL VASOSPASM}

The flow of blood in arteries is caused by a gradient of pressure and is retarded by the forces of friction. This statement embodies Newton's law of motion and the concept of viscosity 15. The mechanism and extent to which flow depends on pressure and forces of friction is shown in Poiseuille equation. A laminar flow within the vessels is directly proportional to the fourth power of the radius of the vessels and inversely proportional to the viscosity of the fluid and the length of the vascular bed 18,32. It is important here to emphasize the effect that a change in vascular caliber would have on flow. Thus, decreasing the radius of a vessel by 50\% should decrease the flow by a factor of 1618

Cerebral vessels are not rigid but are both distensible and capable of contraction, particularly in the precapillary segment. Cerebral vasospasm seen in $\mathrm{SAH}$ is not a generalized phenomenon, but is concentrated in arteries of large caliber in the base of the brain $20,23,45$, while the autoregulation of the micro vessels downstream remains intact. Since the cerebral perfusion pressure (CPP) is decreased by the vasospasm upstream, the microvessels present a profound vasodilation causing an increase in cerebral blood volume (CBV) 20 . At the venous end of the vascular bed, the vessels are collapsible. The craniospinal system in enclosed within a rigid container which has only limited external venting. Thus, the increase in $\mathrm{CBV}$, associated with brain edema due to disruption of the blood brain barrier present in vasospasm $6,23,40$, causes an increase in the intracranial compartment pressure. This high pressure in the extravascular space becomes an important factor and may impair blood flow to the brain 32 .

Vessel stenosis also leads to flow instabilites, turbulence, and increased shear stress on the endothelium 11,18. This increased shear stress associated with an abrupt constriction has been shown to be directly injurious to the endothelium 16,18,41. An acute increase in shear stress may injure and erode the endothelial lining of narrowed arteries. Subsequent platelet aggregation and thrombosis, with their obvious pontential for embolization, suggests a mechanism for ischemia and infarction associated with cerebral vasospasm 18. Morphological changes in the vessel wall are an important component generator of the second phase of the SAH-induced vasospasm. They will be discussed in the next section.

\section{SPASM AND LESION OF THE VESSEL WALL}

In experimental cerebral vasospasm induced by blood injection into the subarachnoid space, immediate vasoconstriction possibly secondary to neural discharge occurs 2,5. Because the delayed spasm begins usually after many hours or days, it appears to be secondary to structural changes in the vessel walls caused during the acute vasoconstriction by biochemical and/or mechanical factors $2,18,23,45$. The persistent and delayed vasospasm appears to be the process 
that is associated with morbidity in patients with $\mathrm{SAH} \mathrm{2,13,23,45.} \mathrm{The} \mathrm{biochemical}$ aspects of the SAH-induced cerebral vasospasm will be the subject of the next section.

After SAH the cerebral basal arterial walls show some or all of the following ultrastructural changes: intimal appearance of vacuoles and dense bodies in endothelial cells, detachment of endothelial cells and intimal thickening. These changes appear 2 hours after SAH, culminate at 3 to 7 days after SAH, and persist up to 1 month after SAH 44. The media of these arterial walls show the moth-eaten contour of muscle cells, appearance of intracytoplasmic vacuoles and dense bodies, appearance of cell debris, enlargement of the interstitial space, and the appearance therein of dense particles 46 . In addition, there is intraluminar platelet adhesion and aggregation with white cell adhesion and thrombus formation, increased endothelial pinocytosis activity or channel formation, intimal swelling, proliferation, degeneration, and desquamation, opening of interendothelial junctions, subendothelial fibrosis, and proliferation of smooth muscle cells, medial infiltration of lymphocytes, plasma cells and macrophages, and the deposition of $\operatorname{IgG}$ and complement, necrosis of smooth muscle cells, corrugation of the internal elastic lamina, degranulation of perivascular nerve terminals and degeneration of perivascular nerves 23,44 . Indeed, a severe injury occurs in the wall of the cerebral vessel.

The healing vessel after SAH morphologically resembles the healing atheroma, in which myofibroblats and collagen also appear. The interstitial deposition of collagen within the vessel was is believed to occur in lock step with the migration and proliferation of myoblasts. Thus, the lumen of the vessel may be held in a contracted phase for weeks to strengthen the injured arterial wall during the healing period 44. A similar contraction phase occurs in skin wounds, semingly related to the appearance of myofibroblasts. As wound edges approximate, collagen deposition maintains the tissue in this constricted phase for further repair 44. It is possible that myofibroblast migration and proliferation could be inhibited by modification of growth factor release 1,44. Also, it is possible that swollen vessel walls may narrow the arteries' lumen 23 .

The vessel injury described is likely to be caused during the acute phase of vasoconstriction 2 . It is due to shear endothelial stress of the arterial endothelial cells that degenerate with opening of the interendothelial tight junctions. It results in marked disturbance in the blood arterial wall barrier or direct action of catecholamines in the smooth muscle cells, or both $2,18,23$. Evidence of endothelial cell erosion and platelet adhesion can be seen as early as 15 minutes after the onset of focal vasospasm 18. On the other hand, 3 and 5 days following $\mathrm{SAH}$ with reserpinized dog's blood, ultrastructural findings of the intima and media of basal truncal arterial wall were entirely normal 46 . While this evidence are suggestive that a shear stress and/or direct action of catecholamines in the vessel walls are the causal factor of the vessel wall lesions, they do not exclude the possibility that the arterial hypertension present during the episode of $\mathrm{SAH}$ is the cause of lesions in the endothelium 23,26 . 


\section{BIOCHEMICAL ASPECTS OF CEREBRAL VASOSPASM}

The principles underlying the entire circulatory system hold good for the cerebral circulation as well. Thus, most investigators interested in arterial smooth muscle have chosen to study arteries from areas outside the brain and have reasoned that arterial smooth muscle cells have the same general biochemical processes involving contraction and relaxation, regardless of the anatomical site of the artery 55 . The present in vitro techniques, using small volume chambers and measuring isometric contractions of arteries segments, allows testing of any biochemical compounds and the comparison of the physiological responses to these compounds by vessels of different anatomical sites 30 . This section will review intracellular messengers and related substances possibly involved in the genesis and control of the cerebral vasospasm.

Calcium - Until now, various agents have been identified which constrict cerebral vessels; these include catecholamine, serotonin and its metabolites, prostaglandins, thromboxane $A_{2}$, whole blood, hemoglobin, erythrocyte breakdown products, fibrinogen degradation products and many others. All these known vasoconstrictive agents may act by many different mechanisms, but they all induce contraction of the smooth muscle of the cerebral vessel by increasing the free intracellular concentration of calcium $3,20,25,51$. Thus, cerebral vasospasm, the sustained contracture of vascular smooth muscle, may be caused by an increase of membrane permeability to $\mathrm{Ca}++$, increased $\mathrm{Ca}++$ mobilization from intracellular stores, decreased $\mathrm{Ca}++$ sarcoplasmic reticulum uptake 47 or theoretically, by an inhibition of $\mathrm{Ca}++$ pumping $31 . \mathrm{Ca}++$ uptake by the sarcoplasmic reticulum appears to be the main process responsible for relaxation since the rate of arterial smooth muscle relaxation after a high $K+$ exposure is much faster than the rate of net loss of $\mathrm{Ca}++$ from the cells 50 . The intracellular calcium activity appears to be regulated by the adenylate and guanylate cyclase systems 7,22. Adenylate cyclase and guanylate cyclase catalyze the hydrolyses of ATP and GTP to cyclic adenosine monophosphate (cAMP) and cyclic guanosine monophosphate (cGMP), respectively 38,47 . The myoplasmic increase of both CAMP and cGMP induces vessel relaxation 22,36 . The relaxing action of cAMP is due to a decrease in the level of myoplasmic free calcium by bringing about a suppression of extracellular calcium influx and by promoting its active uptake by intracellular storage structures. Also, for contraction the presence of the complex $\mathrm{Ca}++$-calmodulin-myosin light-chain kinase is necessary. cAMP also appears to decrease the affinity of myosin-light chain to calmodulin 12 . The mechanism by which cGMP causes relaxation is still not clear. The relaxation induced by nitrates (nitroprusside, glyceryl trinitrate), and endothelium dependent relaxing factor, appear to be caused by an increase in intracellular levels of cGMP 22,36. Although there is an association of high myoplasmic cGMP with low myoplasmic $\mathrm{Ca}++$, further investigation are required to clarify whether there are different pools of $\mathrm{Ca}++$ which can regulate different cellular processes such as phosphorylase a formation and myosin lightchain phosphorylation. A differential effect of cGMP on one or more pools of $\mathrm{Ca}++$ would explain the effects of cGMP on the various $\mathrm{Ca}+-+$ regulated processes 22 . 
Calcium antagonists - According to the classical definition, calcium antagonist drugs or calcium entry blockers inhibit the calcium influx through the excited membrane of smooth muscle. Verapamil and D-600 are thought to act in this way ${ }^{3}$. These agents do not have specificity to the cerebral vessels smooth muscle and tend to cause systemic vasodilation. Obviously, a systemic vasodilation is not desired when the goal is to increase perfusion in the brain. Nimodipine is a new calcium antagonist with special affinity for the receptoroperated calcium channels in cerebral vessels 20,25 . In dogs Nimodipine increases the cerebral blood flow (as measured by $133 \mathrm{X} e$-clearance) much more effectively than the femoral artery blood flow (measured by an electromagnetic flow meter) 25. This increase in cerebral blood flow is not related to the increase in brain metabolism caused by this calcium antagonist 33,34 . Nimodipine is expected to improve cerebral perfusion when it is impaired by spasmogenic agents 25,27 . A recent study has shown a beneficial effect of prophylatic oral administration of Nimodipine 4. However, it was not effective when injected directly in the carotid artery of patients with established SAH cerebral vasospasm 20. Constriction of vessels, which is believed to be produced by mobilization of intracellular calcium stores, is refratory to the action of calcium channel blokers in some vessels 25 . Thus, it is necessary to have agents that act intracellularly by blocking calcium mobilization. Recently, it has been shown that calmodulin antagonists decrease the intensity of basilar artery spasm in experimental SAH 8 Psychotropic drugs, such as phenothiazine and derivatives, have shown a lighaffinity, $\mathrm{Ca}++$-specific binding to calmodulin, forming a calmodulin-calciumpsychotropic complex that cannot activate the calmodulin-sensitive form of enzyme 37 .

Biogenic amines - Adrenergic fibers originating from the locus ceruleus are considered to regulate intracerebral microcirculation. The large arteries at the base of the brain that are involved in the cerebral vasospasm and the superficial arteries of the cortex derive their adrenergic innervation mainly from the superior cervical ganglion 32 . The biphasic cerebral vasospasm seen in SAH is followed by a biphasic catecholamine concentration in the vessel walls and locus ceruleus. It consists of a reduction during the first 24 hours followed by a marked increase at 3 days 35 . The loss of catecholamine-induced fluorescence of the adrenergic fibers innervating the cerebral vessels has been well documented 2,40,53. SAH experimental studies showing immediate disappearance of the catecholamines from the nerve endings of cerebral arteries, and prevention of acute early vascular spasm by $\alpha$ - adrenergic blocking agents have implicated the sympathetic nervous system in the etiology of cerebral vasospasm 2,49,54. The massive release of catecholamines from adrenergic fibers after SAH has also been implicated as the cause of myonecrosis 19. This myonecrosis can be prevented by prior catecholamine depletion. The elevation of catecholamine concentration within arterial walls during the phase of delayed cerebral vasospasm may aggravate the vascular wall contraction during the healing process that follows the vascular myonecrosis 23,44,46. Also, it has been demonstrated that there is an increased reactivity of the cerebral vessel smooth muscle to biogenic amines following subarachnoid hemorrhage 29 . One possible explanation for 
the increased sensitivity to biogenic amines would be a denervation-supersensitivity type of response 40 . Scrotonin (5-HT) is known to cause severe and acute vasoconstriction 14, proliferation of fibroblasts and the contraction of myofibroblasts. Platelets, which are known to aggregate upon the intima surface of vessels following either endothelium injury, vessel rupture or induced spasm, contain virtually all of the 5 -HT in blood 54. Release of vasoactive substances from platelets has been proposed as a possible mechanism of vasospasm generation in SAH and migraine as well 9,51. Also, cerebral artery contraction induced by the Hemoglobin-containing test solution and serum is attenuated or suppressed by the 5-HT antagonists cinaserin and methysergide 48 . Biogenic amines appear to cause not only the initial and brief vasocontriction phase, but are also involved in the generation of vessel wall lesions present in SAH cerebral vasospasm.

Prostaglandins - It has recently been hypothesized that the endothelial damage resulting from $\mathrm{SAH}$ is related to the subsequent arterial narrowing. Current thinking holds that prostacyclin $\left(\mathrm{PGl}_{2}\right)$ synthesis is compromised in the demaged endothelium 43 . Without this vasodilator prostaglandin, the potent vasoconstrictor thromboxane $A_{2} \quad\left(T X A_{2}\right)$ remains unopposed. The imbalance between prostacyclin-thromboxane $A_{2}$ may be directly implicated in the genesis of chronic cerebral vasospasm and ischemic complications following aneurysmal SAH 23,45. Lesions in the endothelium also give rise to a recent hypothesis of a predominance of contractile activity of prostaglandins such as $P G F_{2} \alpha$ and othet contractile agents 10 , due to lack of a still unknown endothelial dependent relaxing factor $17,23,52$. The nature and number of potentially vasoactive compounds in blood may be greatly underestimated and the genesis of vasospasm following subarachnoid hemorrhage may indeed involve multiple factors 8,42 .

\section{CONCLUSION}

Precise information of the mechanisms by which physiological and pathological stimuli act on cerebrovascular smooth muscle is not yet available. Thus, the relationship of these phonomena to the mechanism of autoregulation and to vasospasm are not yet known. However, one is a physiological event, the other pathological. The most obvious difference between the two is the prompt response of physiological constriction or dilation to appropriate drugs or environmental changes, in contrast to the refractory and prolonged (4 weeks or more) narrowing of arterial lumen following SAH. Only the latter should be called vasospasm, a state involving not only the physiological mechanisms of constriction, but also inflammatory and healing processes in a damaged vessel wall. While antagonists of compounds that cause increase of intracellular free $\mathrm{Ca}++$ may have some effect in the early phase of the SAH and migraine, their effect is likely to be tenuous or negligible in the late phase of SAH cerebral vasospasm. In this phase, inhibitors of mitogenic growth factor-induced hyperplasia of the vessel walls may be helpful in minimizing the severity of the delayed SAH cerebral vasospasm.. 


\section{SUMMARY}

Cerebral vasospasm is an important component of pathological entities such as migraine, subarachnoid hemorrhage (SAH), head trauma, post cerebral ischemia and/or hypoxia. The mechanisms underlying cerebral vasospasm in these diseases are not completely understood. Neurochemical and morphological factors involved in the cerebral circulation control are reviewed in this article. The circulatory changes observed after subarachnoid hemorrhage are taken as a model. It is concluded that multiple biochemical, physiological and morphological factors are involved in the cerebral vascular responses after SAH. Possible treatment alternatives for cerebral vasospasm based on its etiology are discussed.

\section{RESUMO}

\section{Vasoespasmo cerebral.}

Vasoespasmo cerebral ocorre em patologias como enxaqueca, hemorragia subaracnóidea, trauma de crânio, após isquemia e/ou hipoxia. A fisiopatologia do vasoespasmo cerebral nestas patologias não está completamente desvendada. Neste artigo são analisados os fatores neuroquímicos e morfológicos responsáveis pelo controle circulatório cerebral. As alterações circulatórias que seguem a hemorragia subaracnóidea são utilizadas como exemplo. Conclui-se que fatores bioquímicos, fisiológicos e morfológicos são responsáveis pelas manifestações vasculares que ocorrem após a hemorragia subaracnóidea. Alternativas de tratamento do vasoespasmo cerebral são discutidas.

\section{REFERENCES}

1. ALEXANDER III, E.; BLACK, P.M.C.L.; LISZCZAK, T.M.; ZERVAS, N.T. Delayed CSF lavage for arteriographic and morphological vasospasm after experimental SAH. J. Neurosurg 63:949, 1985.

2. ALKSNE, J.F.; GREENHOOT, J.H. - Experimental catecholamine-induced cerebral vasospasm: myonecrosis in vessel wall, J. Neurosur 41:440, 1974.

3. ALLEN, G.S. - Cerebral arterial spasm: a discussion of present and future research. Neurosurgery 1:142, 1977.

4. ALLEN, G.S.; AHN, H.S.; PREZIOSI, T.J. et al. - Cerebral arterial spasm - a controlled trial of nimodipine in patients with subarachnoid hemorrhage. N. Engl. J. Med. 308:619, 1983.

5. BAUMBACH, G.L.; HEISTAD, D.D. - Effect of sympathetic stimulation and changes in arterial pressure on segmental resistance of cerebral vessels in rabbits and cats. Cir. Res. 52:527, 1983.

6. BEKS, J.W.F. - Cerebral vasospasm and increased intracranial pressure. In R.H. Wilkins (ed.): Cerebral Arterial Spasm. Baltimore, William \& Wilkins, 1980, p. 412.

7. BERRIDGE, M.J. - Cellular control through interaction between nucleotides and calcium. Advances in Cyclic Nucleotide and Protein Phosphorylation Res. 17:329, 1984.

8. BLAUMANIS, O.R.; GRADY, P.A. - Experimental cerebral vasospasm: resolution by chloropromazine. Surg. Neurol, 17:263, 1982.

9. BURNSTOCK, G. - Nervous control of cerebral blood vessels: a new hypothesis of the mechanism underlying migraine. In F.C. Rose \& K.J.Ailkha (eds.): Progress 
in Migraine Research 1. London, Pitmán Press, 1981. p. 17.

10. BUSIJA D.W. - Role of prostaglandins in modulating synmpathetic vasoconstriction in the cerebral circulation in anesthetized rabbits. JCBFM 17:24, 1985.

11. CLARK, C. - Turbulent velocity measurements in a model of aortic stenosis. J. Biomech. 9:677, 1976.

12. CONTI, M.A.; ADELSTEIN, R.S. - Phosphorylation by cyclic adenosine 3':5-monophosphate-dependent protein kinase regulates myosin light chain kinase. Fed. Proc. $39: 1569,1980$.

13. ECKER, A.; RIEMENSCHNEIDER, P.A. - Arteriographic demonstration of spasn of the intracrantal arteries: with special reference to saccular arterial aneurysms. J. Neurosurg. 8:660, 1951.

14. EDVINSSON, L.; HARDEBO, J.E.; OWMAN, C.H. - Pharmacological analysis of 5-HT receptors in isolated intracranial and extracranial vessels of rat and man. Cir. Res. 42:143, 1978.

15. FORRESTER, J.H.; YOUNG, D.F. - Flow through a converging-diverging tube and its implication in occlusive vascular disease: 1 . Theorectical development. J. Bicmech. $3: 297,1970$.

16. FRY, D.L. - Certain histological and chemical responses of the vascular interface to acutely induced mechanical stress in the aorta of the dog. Cir. Res. 24:93, 1969.

17. FURCHGOT'T, R.F. - Role of endothelium in responses of vascular smooth muscle. Cir. Res. 53:557, 1983.

18. GRADY, P.A.; BLUAMANIS, O.R.; NELSON E.R. - Morphology and flow dynamies of focal arterial constriction. In R.H. Wilkins (ed.): Cerebral Arterial Spasm. Baltimore, William \& Wilkins, 1980, p. 107.

19. GREENHOOT, J.H.; REICHENBACH, D.D. - Cardiac injury and subarachnoid hemorrhage, a clinical pathological, physiological correlation. J. Neurosur 30:521, 1969.

20. GROTENHUIS, H.A.; BETTAG, W.; FIEBACH, B.J.O.; DABIR, K. - Intracarotid slow bolus injection of nimodipine during angiography for treatment of cerebral vasospasm after SAH. J. Neurosur 61:231, 1984.

21. GRUBB, R.L.; RAICHLE, M.E.; EICHLINS J.O.; GADO, M.H. - Effects of subarachnoid hemorrhage on cerebral blood volume, blood flow, and oxygen utilization in humans. J. Neurosurg 46:446, 1977.

22. JOHNSON, R.M.; LINCOLN, T.M. - Effects of nitroprusside, glyceryl trinitrate, and 8-bromo cyclic GMP on phosphorylase a formation and myosin light chain phosphorylation in rat aorta. Mol. Pharmacol. 27:333, 1985.

23. KASSELL, N.F.; SASAKI, 'T.; COLOHAN, A.R.T.; NAZAR, G. - Cerebral vasospasm following aneurysmal subarachnoid hemorrhage. Stroke 16:562, 1985.

24. KASSEL, N.F.; PEERLESS, S.J.; DRAKE, C.G. - Acute proliferative vasculopthy? I. Hypothesis. In R.H. Wilkins (ed.): Cerebral Arterial Spasm. Baltimore, William \& Wilkins, 1980, p. 85.

25. KAZDA, S.; TOWART, R. - Nimodipine: a new calcium antagonist drug with a preferential cerebrovascular action. Acta. Neurochir. 63:259, 1982.

¿6. KONTOS, H.A.; WEI, E.P.; DIETRICH, D.; NAVARY, R.M.; POVLISHOCK, J.T.; GHATAK, N.R.; ELLIS, E.F.: PATTERSON, J.L. Jr. - Mechanism of cerebral arteriolar abnormalities after acute hypertension. Am.. J.. Physiol. 240 (Heart. Circ. Physiol. 9): H511, 1981.

27. KRUEGER, C.; WEIR, B.; NOSKO, M.; COOK, D.; NORRIS, S. - Nimodtpine and chronic vasospasm in monkeys: 2 - Pharmacological studies of vessels in spasm. Neurosurgery $16: 137,1985$.

28. LASSEN, N.A. - Brain. In P.C. Johnson (ed.): Peripheral Circulation. New York, John Wiley \& Sons, 1978 , p. 337.

29. LOBATO, R.D.; MANN, J.; SALAICES, M.; RIVILLA, F.; BURGOS, J. Cerebrovascular reactivity to noradrenaline and serotonin following experimental subarachnoid hemorrhage. J. Neurosurg. 53:480, 1980.

30. McCULLOCH, J.; EVINSSON, L. - Cerebrovascular smooth muscle reactivity a critical appraisal of in vitro and in situ techniques. JCBFM 4:129, 1984. 
31. MILLER, C.A. - Biochemistry of vascular smooth muscle: Contractile mechanism of human basilar artery. In R.H. Wilkins (ed.): Cerebral Arterial Spasm. Baltimore, William \& Wilkins, 1980, p. 68.

32. MILLeR, J.D. - Control of the cerebral circulation. In R.H. Wilkins (ed.): Cerebral Arterial Spasm. Baltimore, William \& Wilkins, 1980, p. 76.

33. MOHAMED, A.A.; MENDELOW, A.D.: TEASDALE, G.M.; HARPER, A.M.; Mc CULLOCH, J. - Effect of the calcium antagonist nimodipine on local cerebral blood flow and metabolic coupling. JCBFM 5:26, 1985.

34. MOHAMED, A.A.; MCCULLOCH, J.; MENDELOW, A.D.; TEASDALE, G.M.; HARPER, A.M. - Effect of the calcium antagonist nimodipine on local cerebral blood flow: relationship to arterial blood pressure. JCBFM 4:206, 1984.

35. MOROOKA, H. - Cerebral arterie' spasm: I. Adrenergic mechanism in experimental cerebral vasospasm. Acta. Med. Okayama 32:23, 1978.

36. PEACH, M.J.; LOEB, A.L.; SINGER, H.A.; SAYE, J. - Endothelium-derived vascular relaxing factor. Hypertension 7 (suppl. 1): 1, 1985.

37. NAKANO, M.; TANI, E.; FUKUMORI, T.; YOKOTA, M. - Effects of chlorpromazine on experimental delayed cerebral vasospasm. J. Neurosurg. 61:857, 1984.

38. NORWOOD, C.W. - A review of recent advances in vascular smooth muscle pharmacology. In R.H. Wilkins (ed.). Cerebral Arterial Spasm. Baltimore, William \& Wilkins, 1980, p. 57.

39. OLESEN, J.; LAURITZEN, J. - The role of vasoconstriction in the pathogenesis of inigraine. In W.D. Amery, J.M.V. Nueten \& A. Wauquier (cds.): Pharmacological Basis of Migrain Therapy. London. Pitman Press, 1984, p. 7.

40. PICKARD, J.D.; PERRY, S. - Spectrum of altered reactivity of isolated cerebral arteries following subarachnoid hemorrhage: response to potassium, pH, noracirenaline, 5-hydroxytryptamine, and sodium loading. JCBFM 4:599, 1984.

41. RAY, G.; DAVIDS, N. - Shear stress analysis of blood-endothelial surface in inlet section of artery with plugging. J. Biomechanics 3:99, 1970.

42. SASAKI, T.; ASANO, T.; TAKAKURA, K.; SANO, K.; KASSELL, N.F. - Nature of the vasoactive substance in CSF from patients with subarachnoid hemorrhage. J. Neurosurg. 60:1186, 1984.

43. SHOHAMI, E.; SIDI, A. - Accumulation of prostacyclin in rat brain during hemorrhagic hypotension - Possible role of $\mathbf{P G I}_{2}$ in autoregulation. JCBFM $4: 107$, 1984 .

44. SMITH, R.R.; CLOWER, B.R.; GROTENDORST, G.M.; YABYNO, N.; CRUSE, J.M. - Arterial wall changes in early human vasospasm. Neurosurgery 16:171, 1985.

45. SPALLONE, A. - Cerebral vaosopasm as a complication of aneurysmal subarachnoid hemorrhage: brief review. Ital. J, NeuroI. Sci. 6:19, 1985.

46. TANABE, Y.; SAKATA, K.; YAMADA, H.; ITO, T.; TAKADA, M. - Cerebral vasospasm and ultrastructural changes in cerebral arterial wall an experimental study. J. Neurosurg. 49:229, 1978.

47. TANI, E.; YAMAGATA, S.; MAEDA, Y.; ITO, Y. - Cytochemical demonstration of adenylate and guanylate cyclases in vascular smooth muscle of circle of Willis. J. Neurosur. 49:239, 1978.

48. TODA, N.; SHIMIZX, K.; OHTA, T. - Mechanism of cerebral arterial contraction induced by blood constituents. J. Neurosurg. 53:312, 1980.

49. TSUKAHARA, T.; TANIGYCHI, T.; FUJIWARA, M.; HANDA, J.; NICHIKAMA, M. - Alterations in alpha adrenergic receptors in human cerebral artery after subarachnoid hemorrhage. Stroke 16:53, 1985.

50. VAN BREEMEN, C.; SIEGEL, B.; KALINOSKI, L.; AERA, P.; HWANG, O. The $\mathbf{C a}++$ cycle of arterial smooth muscle. Cerebral Arterial Spasm. Baltimore, Willtam and Wilkins, 1980, p. 61.

51. VAN NUETEN, J.M. - Antivasoconstrictor effects of drugs used in migrain therapy. In W.D. Amery, J.M.V. Nueten and A. Wauquier (eds): Pharmacological Basis of Migrain Therapy Pitman Press, London, 1984, p. 19. 
52. WEI, E.P.; KONTOS, H.A.; CHRISTMAN, C.W.; DeWITT, DS; POVLISHOCK, J.T. - Superoxide gencration and reversal of acetycholine-induced cerebral arteriolar dilation after acute hypertension. Cir. Res. (In press).

53. WELLUM, G.R.; PETERSON, J.W.; ZERVAS, N.T. - The relevance of in vitro smooth muscle experiments of cerebral vasospasm. Stroke 6:573, 1985.

54. YOSHIOKA, J.; CIOWER, B.R.; SMITH, R.R. - The angiopathy of subarachnoid hemorrhage. I. Role of vessel wall catecholamines. Stroke 15:288, 1984.

55. ZIJLSTRA, W.G. - Physiology of the cerebral circulation. In J.M. Minderhoud (ed.): Cerebral Blood Flow, Basic Knowledge and Clinical Implications. Exerpta Medica, Amsterdam, 1981.

9 Hawthorne Place $9 B$ - 02114, Boston, Mass. - U.\$.A. 